\title{
SOCIALIZAÇÃO E ETNICIDADE: A QUESTÃO ESCOLAR TEUTO-BRASILEIRA (1850-1937)
}

Giralda Seyferth

No dia 6 de abril de 2017 faleceu nossa colega, a antropóloga Giralda Seyfert, Pesquisadora da imigração alemã no sul do Brasil, e referência em temas como relações raciais, etnicidade e campesinato. Professora do Departamento de Antropologia do Museu Nacional desde os anos 1970, inicialmente na área de Antropologia Física, foi aluna de mestrado das primeiras turmas do PPGAS, onde defendeu sua dissertação sobre o Vale do Itajaí em 1973, tornando-se sua professora mesmo antes da defesa de seu doutorado. Desde essa época, portanto, até seu falecimento, o Programa pôde contar com sua dedicação institucional, sua competência intelectual, sua erudição e seu bom humor. Ocupou ainda diversos cargos administrativos, tanto na UFRJ como em associações científicas e agências de fomento. Formou inúmeros professores e pesquisadores em atuação no Brasil e no exterior, coordenou por muitos anos os Grupos de Trabalho sobre Migrações Internacionais da Associação Nacional de Pós-Graduação e Pesquisa em Ciências Sociais (Anpocs), da Reunião Brasileira de Antropologia (RBA) e da Reunião de Antropologia do Mercosul (RAM), tendo sido cofundadora do Núcleo Interdisciplinar de Estudos Migratórios (Niem). Colega agregadora, professora competente, orientadora generosa, seu falecimento deixou todos nós um pouco órfãos.

O artigo original que trazemos neste número de Mana, "Socialização e etnicidade: a questão escolar teuto-brasileira (1850-1937)", foi apresentado inicialmente no workshop "Reception, Integration and Socialization of
Immigrants", no International Metropolis Conference 2014, em Milão. Em função da proposta geral do encontro - um congresso internacional sobre migrações, de cuja versão anterior, em 2011, nos Açores, Giralda também participara - o texto versa sobre um tema não muito frequente em sua obra: a educação de imigrantes e seus descendentes. Mas mesmo com um tema singular, o trabalho traz características fundamentais da escrita de Giralda: a profundidade teórica, o uso inteligente das fontes e, sobretudo, a capacidade de entrelaçar o passado com o presente, utilizando documentos do século XIX e início do século XX para discutir questões absolutamente contemporâneas.

O plano inicial era que o trabalho fosse publicado em livro com os textos apresentados no workshop, mas, denunciando outra característica de Giralda, só ela preparou o texto no prazo. Sendo assim, quando pensamos em homenageá-la, consideramos a oportunidade de publicar este trabalho ainda inédito no Brasil, o último texto completo que ela escreveu.

Agradecemos à sua família pela cessão dos direitos para a publicação desta lembrança, uma forma de tornar públicos a saudade e o reconhecimento pela enorme oportunidade que foi conviver com Giralda e de tê-la em nosso Programa.

Renata Menezes, editora de Mana \& Miriam Santos, ex-orientanda de Giralda Seyferth. 
Os primeiros imigrantes alemães destinados ao projeto de colonização estrangeira do governo imperial brasileiro chegaram ao Brasil em 1824. Desde o início foram identificados oficialmente como colonos, recebendo concessão de terras para cultivo familiar ou se estabelecendo nos povoados surgidos nos núcleos coloniais. Ao longo do século XIX, e nas três primeiras décadas do século XX, uma parte significativa dos mais de 360 mil imigrantes de língua alemã ${ }^{1}$ se estabeleceu principalmente nas áreas coloniais da região Sul. Nesse período histórico o Estado falhou em assegurar plenamente o acesso à escola pública para os filhos dos colonos, dadas as condições precárias de localização num processo de povoamento, motivando a mobilização de lideranças comunitárias, religiosas e laicas para a organização de um sistema escolar particular de ensino na língua materna, que teve continuidade mesmo depois do período de desbravamento e do crescimento urbano dos núcleos coloniais.

A socialização étnica, apoiada na diferença cultural, defendia a pluralidade derivada da imigração e uma identidade teuto-brasileira, e foi objeto de crítica contundente do nacionalismo, sobretudo depois do advento da República, em 1889. As escolas denominadas "alemãs" perduraram até 1937, quando o governo, preocupado com a assimilação, nacionalizou o ensino, atingindo também outros grupos de imigrantes e descendentes. Neste trabalho pretendo abordar os fatores condicionantes da pertença étnica teuto-brasileira que marcaram a socialização infantil nessas escolas, dando atenção ao conflito entre etnicidade e nacionalismo e sua consequência: o fechamento e/ou a mudança radical nas diretrizes das escolas no sentido do "abrasileiramento" em nome da segurança nacional.

\section{I}

A colonização estrangeira no Brasil realizou-se em terras devolutas, isto é, públicas, incultas ou simplesmente consideradas não ocupadas, afastadas das regiões de predominância das grandes propriedades monocultoras. Ela ocorreu sobretudo no sul por uma razão geopolítica, a consolidação das fronteiras internacionais numa região de baixa densidade populacional, mas também visava à produção policultora para abastecimento e a "civilização" dos indígenas. Os dois últimos desideratos motivaram o direcionamento da colonização para as terras altas da província do Espírito Santo, iniciada em 1847 com a fundação de uma colônia alemã. 
Na primeira fase da colonização estrangeira (1824-1830) a concessão de terras era gratuita e cada família recebia aproximadamente 70 hectares; o número de entradas, porém, não foi significativo e os núcleos (ao todo, oito) receberam colonos alemães. Houve uma interrupção do movimento imigratório entre 1830 e 1845 motivada pela falta de recursos e pela guerra civil no sul (a Revolução Farroupilha, de 1835 a 1845), e a retomada ocorreu com a fundação de colônias alemãs no sul, no Espírito Santo e em Petrópolis (Rio de Janeiro), num momento em que se discutia no Parlamento a nova regulamentação fundiária que também contemplou a colonização.

O modelo de "núcleo colonial" vigente depois da promulgação da Lei de Terras (Lei 601, de 1850) e suas sucedâneas estabeleceu a concessão de terras por compra, cabendo a cada família aproximadamente 25 hectares (bem menos do que as concessões anteriores a 1830). Como a colonização se processou especialmente nas bacias hidrográficas, os chamados "lotes coloniais", destinados ao cultivo com mão de obra familiar, foram demarcados ao longo dos rios e seus afluentes. As famílias deviam fixar sua residência na terra recebida e, nesse sentido, a "linha colonial" (expressão que designava o caminho aberto na mata a partir do qual os lotes eram demarcados) tornou-se também a comunidade de referência para seus habitantes. O contraponto dessas comunidades rurais ou linhas era o povoado (previsto na legislação), em geral situado nas margens do rio, lugar da administração colonial e dos alojamentos, onde os imigrantes esperavam precariamente a concessão das terras. Nele surgiram as primeiras casas comerciais, igrejas e escolas.

Na retomada da colonização estrangeira, em 1845, o governo imperial passou a dividir com as províncias o controle das terras devolutas e as despesas com essa imigração dirigida, ${ }^{2}$ e a abrir espaço para a atuação de associações e empresas particulares criadas para estabelecer núcleos coloniais, assumindo os encargos (de aliciamento e fixação dos imigrantes, e das obras públicas, aí compreendidas a abertura de vias de comunicação e demarcação das terras).

Essa forma de ocupação territorial intensificou-se depois de $1850^{3} \mathrm{e}$ se expandiu para todo o planalto setentrional, produzindo um campesinato cultural e economicamente diferenciado, num contexto inicial de "zona pioneira" (conforme definição de Waibel 1958:264). Este é um conceito apropriado da ideia de fronteira referida à ocupação do meio oeste dos Estados Unidos e supõe a expansão da civilização sertão adentro. Nos termos de Waibel (1958:206), um geógrafo, as regiões colonizadas por imigrantes europeus no sul do Brasil apresentam paisagens culturais diferenciadas, com "comunidades próprias". 
Até o meio da década de 1870 a maioria dos colonos era de origem alemã: as primeiras colônias italianas só surgiram depois de 1875. As principais colônias alemãs foram estabelecidas no século XIX e tornaram-se mais conhecidas pelas diferenças culturais e pelo desenvolvimento, na medida em que povoados previstos em cada núcleo cresceram e se industrializaram, e lideranças étnicas surgiram no campo político reivindicando a plena cidadania e o direito à germanidade.

Ao longo de mais de um século, imigrantes alemães e muitos dos seus descendentes ( $2^{\mathrm{a}}$ e $3^{\mathrm{a}}$ gerações) participaram da fundação de aproximadamente duas centenas de núcleos coloniais no sul, alguns dos quais se tornaram exemplos do "enquistamento étnico", expressão metafórica usada para condenar a pluralidade cultural. Mais do que a paisagem cultural diferenciada assinalada por Waibel, o que chamou a atenção do nacionalismo brasileiro foi a organização comunitária étnica que incluía associações recreativas, culturais, beneficentes, o uso cotidiano da língua alemã, a proliferação de jornais, revistas, almanaques e uma literatura ficcional publicados na língua alemã, e a adoção de uma identidade - Deutschbrasilianer - assinalando a pertença étnica ao povo (ou nação) alemão, bem como a cidadania brasileira. Nesse contexto, a escola comunitária teuto-brasileira transformou-se num espaço da germanidade, do pluralismo cultural reivindicado como um direito de imigrantes e descendentes, coisa particularmente visível em lugares paradigmáticos como São Leopoldo (RS), a primeira colônia, Blumenau e Brusque (no Vale do Itajaí, SC), Joinville (SC), entre outros.

A imigração alemã, porém, não ficou restrita aos núcleos coloniais e suas cidades emergentes. Os primeiros imigrantes dessa origem estabeleceram-se na cidade do Rio de Janeiro logo após a abertura dos portos promovida pelo governo português, em 1808. Aliás, este grupo fundou a primeira associação de perfil étnico em terras brasileiras, a Gesellschaft Germania, em 1821. Afinal, a legislação que regulamentou a entrada e o estabelecimento de estrangeiros ao longo do tempo deu destaque à imigração dirigida para núcleos coloniais (ainda observável no Decreto-lei 7.967, de 1945, que vigorou depois da Segunda Guerra Mundial). Mas também não coibiu a desejada imigração espontânea que produziu outras formas de inserção, principalmente nas cidades, inclusive naquelas que se desenvolveram nos núcleos coloniais, impulsionadas pela industrialização. De fato, muitos imigrantes se fixaram em cidades situadas fora do contexto colonial, caso das capitais sulinas (Porto Alegre, Florianópolis, Curitiba), de São Paulo e Campinas, e no Rio de Janeiro, onde também se organizaram comunitariamente, fundando escolas e associações, concentrando-se em bairros. Por outro lado, uma parcela dos imigrantes e descendentes, inicialmente dirigidos para o 
regime de colonização, migrou para as cidades especialmente por causa das dificuldades encontradas na situação de desbravamento. Havia, pois, circulação de pessoas e ideias entre os dois contextos (colonial e urbano), refletida também na organização escolar teuto-brasileira.

Apesar da inserção urbana mais ampla, e seu efeito mais óbvio, e o contato com a sociedade nacional, as regiões de colonização chamaram a atenção do nacionalismo por causa do distanciamento em relação aos padrões culturais brasileiros e do discurso sobre legitimidade étnica que ressaltou a situação de frente pioneira característica da ocupação das áreas florestais, e o ideal de Deutschtum (germanismo, germanidade) usado como indicador de uma identidade étnica, mas que também possuía um componente econômico e civilizador vinculado ao desbravamento e ao progresso colonial.

As escolas teuto-brasileiras, com ensino ministrado na língua alemã, surgiram no contexto colonial desde os primórdios, atendendo à necessidade de alfabetização dos filhos dos colonos. Na maioria das colônias (administradas pelo Estado ou por empresas colonizadoras), o período do desbravamento (localização das levas de imigrantes nas linhas) foi marcado por dificuldades financeiras que atrasaram a abertura de caminhos e a demarcação das terras em função dos altos índices de mortalidade e atendimento médico precário e da lenta adaptação às condições locais, envolvendo o enfrentamento da floresta, a morada precária e a mudança de hábitos alimentares. Nessa situação adversa relatada na literatura pertinente, nos escritos mnemônicos e cartas de colonos e na documentação oficial dos administradores, entre as muitas reivindicações estava incluída a questão da educação básica. De fato, o Estado não estava inteiramente ausente em relação à educação, mas não priorizou a criação de escolas; autorizou, porém, a contratação de professores, localizando a escola (pública) nos povoados.

No Vale do Itajaí (SC), onde foram fundados diversos núcleos coloniais na segunda metade do século XIX, as escolas públicas eram insuficientes para atender à demanda e praticamente inacessíveis para os filhos dos colonos localizados nas linhas mais afastadas do Stadtplatz (termo designativo dos povoados). A ausência relativa do Estado motivou a ordenação da "escola alemã" pelo fundador da principal colônia dessa região, Hermann Blumenau, e a criação de escolas comunitárias e outras de filiação religiosa (isto é, mantidas pelas igrejas católica e evangélica luterana). Ali, no século XIX, o número de escolas particulares era superior ao das escolas públicas, conforme registro de Wiederkeher (2014). 
O caso de Blumenau é apenas exemplo de uma situação comum a outros núcleos coloniais, coisa que aponta para uma motivação inicialmente despegada da etnicidade. Como observou Kreutz (1994:15), ainda no século XVIII, em alguns estados alemães, a educação passou a ser vista "sob o prisma político social, realçando-se a responsabilidade do Estado na educação". E no início do século XIX a educação pública tornou-se uma realidade, a partir da Prússia, com a difusão geral do ensino elementar. Houve oposição à laicização do ensino, principalmente por parte da Igreja Católica, dada a natureza confessional das escolas particulares. Mas no período histórico da emigração a escola pública era uma realidade, e a maior parte dos imigrantes localizados em áreas coloniais, mesmo os de procedência rural, era alfabetizada. Este dado é um bom indicador da importância atribuída à educação elementar pelos colonos, e explica a constância das petições reivindicando escolas públicas. Na observação de Willems $(1946: 378,381)$, o ensino era obrigatório nas zonas rurais da Alemanha no século XIX, e nas aldeias existia o ensino gratuito em escolas mantidas pelo poder público. Por isso os imigrantes chamaram a atenção para a responsabilidade do Estado em relação ao ensino elementar; diante da omissão do Estado, tomaram a iniciativa de cuidar do ensino dos filhos.

A demanda por escolas públicas, apenas parcialmente atendida, foi um dos motivos da multiplicação das escolas teuto-brasileiras. Willems mencionou a inexatidão das estatísticas, mas incluiu dados apresentados por outros autores que mostram o crescimento numérico das escolas depois da Primeira Guerra Mundial, quando se intensificou o debate sobre a nacionalização e a exigência do aprendizado da língua portuguesa. Segundo os dados reproduzidos por Willems (1940:292), em 1920 existiam 787 escolas no Rio Grande do Sul, número que aumentou para 951 em 1930. Num outro balanço estatístico, referido à presença de escolas em vários estados, em 1930 foram computadas 900 escolas no Rio Grande do Sul, 180 em Santa Catarina, 40 no Paraná, 100 no Espírito Santo, 25 em São Paulo, cinco no Rio de Janeiro, sete em Minas Gerais, e oito em "outros lugares" - totalizando 1.260 escolas. $^{4}$

Em alguns municípios a desproporção entre as escolas públicas e as particulares era bastante expressiva. Como exemplo, Fouquet (1974:170) menciona que em 1917 havia 10 escolas públicas e 113 particulares no município de Blumenau, e cinco públicas e 64 particulares no município de Joinville - região ao norte do estado de Santa Catarina, onde predominou a colonização com imigrantes de origem germânica. Naquele ano ocorreu a declaração do estado de guerra com a Alemanha e, em consequência, as atividades nas escolas foram suspensas, e só voltaram a funcionar em 1919. 
Nesse intervalo, um grande número de crianças ficou sem aulas, porque não puderam ser matriculadas em escolas públicas. Talvez por isto o governo tenha autorizado o funcionamento delas depois da guerra, tendo permitido um aumento do número de estabelecimentos, apesar do acirramento do nacionalismo assimilacionista e sua retórica de "perigo alemão".

Na prática, desde a década de 1920, os governos estaduais criaram mais escolas públicas, apostando no atrativo da gratuidade, principalmente para os filhos dos colonos que tinham dificuldade para pagar as mensalidades. Nesse sentido, a escola pública tornou-se uma opção para o colono pobre (Willems 1946:408), mais do que para as classes média e alta urbanas, apesar dos problemas de aprendizagem causados pelos desentendimentos linguísticos entre os alunos e seus professores brasileiros, assinalados por Kreutz (1994:28). Mas, por outro lado, quando a nacionalização começou, em 1938, existiam no Brasil 1.500 escolas teuto-brasileiras, boa parte delas administradas por ordens religiosas católicas e pelas comunidades evangélicas luteranas (cf. Dalbey 1970; Kreutz 1994). ${ }^{5}$

Num artigo sobre a organização escolar, publicado no volume comemorativo do centenário da imigração alemã em Santa Catarina, organizado por Entres (1929), Marcos Konder enfatizou a importância atribuída pelos imigrantes ao binômio religião-escola, considerado "necessidade indispensável", justificando assim o ensino particular diante da omissão do Estado. O autor expressou sua crença nas virtudes do ensino particular em língua alemã, porém defendeu o aprendizado da língua portuguesa por sua utilidade prática, numa clara vinculação à pertença étnica teuto-brasileira. O teor laudatório do texto, acentuando o valor eurístico atribuído à "educação em casa e na escola", apela para o passado pioneiro e suas dificuldades (Konder 1929:213-221), eventualmente reconhecidas por alguns defensores radicais do "abrasileiramento" com posicionamento crítico em relação às políticas de imigração e colonização de governos anteriores à Revolução de $1930 .{ }^{6}$

Tal posicionamento pode ser observado num famoso discurso conciliador pronunciado pelo presidente da República, Getúlio Vargas, num banquete em sua homenagem realizado em 1940, em Blumenau, a principal cidade do Vale do Itajaí, região considerada exemplo de um germanismo ameaçador da imaginada unidade da nação. O discurso foi destacado por Fouquet (1974:169) e nele o presidente criticou a política de colonização do Império e da República Velha, afirmando que a culpa pela ausência de assimilação cabia aos governantes que deixaram os imigrantes em isolamento "no meio de imensas florestas", onde "só pediam duas coisas, escolas e estradas, estradas e escolas". A fala demagógica, culpando governos anteriores pela intolerável situação de distintividade étnica, procurou atenuar a acusação 
de "enquistamento" (ou, mais precisamente, de ausência de brasilidade e patriotismo) que motivou a intervenção (prática e simbólica) nacionalizadora, particularmente violenta nas áreas coloniais do sul do Brasil. Afinal, o regime ditatorial do Estado Novo, iniciado em 1937, instituiu a campanha de "abrasileiramento" forçado, com intervenção na organização comunitária de imigrantes e descendentes, começando pela nacionalização do ensino que desarticulou a rede escolar teuto-brasileira.

Mas a referência de Vargas a escolas e estradas, metáforas do isolamento dos colonos, revela uma situação real enfrentada na maioria dos núcleos coloniais, inclusive nas primeiras décadas do século XX. A abertura de escolas e estradas era a principal reivindicação dos imigrantes, mesmo depois do início difícil do desbravamento (cf. Seyferth 2014), embora a situação precária do ensino público em áreas de colonização não fosse muito diferente do resto do país. De fato, apesar da menção de alguns autores à presença de analfabetos em algumas áreas coloniais (especialmente no século XIX), os índices de alfabetismo eram altos na população teuto-brasileira, e isto foi atribuído às escolas elementares com ensino na língua materna, até mesmo com as precárias condições iniciais da colonização (cf. Willems 1946, cap. XII; Fouquet 1974:171).

O ensino na língua alemã e a multiplicação dessas escolas nas áreas de colonização no sul aparentemente não causaram preocupação no âmbito da administração pública durante o Império mas, desde o início, a situação foi criticada por setores nacionalistas da sociedade brasileira preocupados com a assimilação, assunto transformado em problema de segurança nacional a partir de 1889. Mesmo assim, esse sistema de ensino, formando uma rede de escolas particulares através da Deutsche Schulverein, só foi enquadrada nos parâmetros gerais (inclusive curriculares) do Ministério da Educação a partir de 1938, com a proibição do ensino em língua estrangeira e a exclusão dos professores que não eram brasileiros natos. De fato, na década de 1930, diante da iminência da nacionalização, exigida em nome da unidade da nação, também recrudesceu o discurso identitário teuto-brasileiro, que percebia a escola como um dos pilares da germanidade, pois ali era ensinada a língua materna, elemento essencial da diferença cultural.

A reivindicação inicial do ensino público como algo inerente à cidadania aos poucos deu lugar a um sistema de ensino particular que passou a incorporar uma dimensão étnica teuto-brasileira, articulada à pluralidade cultural de um país de imigração. No início do século XX, dada a perspectiva de um nacionalismo germânico etnizado, poucas escolas ensinavam a língua vernácula (o português); ela só foi incorporada aos currículos quando o debate sobre o "abrasileiramento" ficou mais acirrado, e a própria integração socioeconômica tornou o bilinguismo indispensável, instrumental. 
III

No que consistia, então, a "escola alemã" (expressão mais comumente usada na literatura pertinente), e mais apropriadamente denominada teuto-brasileira (cf. Seyferth 1982; Kreutz 1994; Rambo 1994)? Existem algumas diferenças curriculares entre as escolas católicas, evangélicas e comunitárias. Nas primeiras, a religião tinha um papel fundamental, pois a religiosidade aparecia ligada à noção de Deutschtum (germanidade). Vicejaram os estabelecimentos de ensino sob administração de ordens religiosas católicas (caso dos jesuítas no Rio Grande do Sul, e dos padres do Sagrado Coração de Jesus, em Santa Catarina), ou da Igreja Evangélica Luterana, apesar do empenho de algumas lideranças coloniais (caso de Herman Blumenau) em prol da regulação não confessional, defendendo uma escola voltada para a questão da cidadania e do progresso.

Na prática, religião, cidadania, herança cultural germânica e a realidade da colonização faziam parte da grade curricular, juntamente com o ensino da língua alemã, eventualmente também da língua portuguesa, além das disciplinas geografia, história, matemática e ciências naturais. ${ }^{7}$ As aulas eram ministradas em alemão, razão maior da crítica assimilacionista. Afinal, na percepção do nacionalismo brasileiro, nessas escolas era dada maior relevância à História da Alemanha em detrimento da História do Brasil, assunto que, junto com a língua, era o cerne da "questão escolar" teuto-brasileira. Nesta perspectiva, a socialização ali produzida não podia formar verdadeiros cidadãos brasileiros, muito menos patriotas, pois reforçava uma identidade espúria ressaltada também na socialização primária do lar.

Tais assuntos foram usados desde o início da República para condenar o "enquistamento étnico" e exigir o abrasileiramento, pois também o ensino da língua vernácula estava prejudicado nessas escolas por ser aprendida, eventualmente, como segunda língua, situação que evocava o "perigo alemão"8 como demarcador do distanciamento cultural em relação à sociedade nacional. A própria inter-relação das escolas através das associações, das publicações e dos livros didáticos apontava para a relevância dessa "questão escolar" em âmbito nacional.

Nos primórdios das colônias as escolas comunitárias tiveram papel fundamental para garantir a alfabetização dos filhos dos colonos. Diante das sucessivas reivindicações, foram concedidas verbas públicas para o pagamento de professoras que ensinavam nas escolas localizadas nos povoados onde estavam estabelecidas as administrações coloniais. ${ }^{9}$ Mas esse formato inicial de escola pública não atendia à demanda das famílias que estavam nas linhas coloniais. Como observei num trabalho relativo ao Vale do Itajaí 
(Seyferth 1982), houve certa progressão nas linhas, pois nos primeiros anos as aulas, quando possível, eram ministradas no lar (processo chamado de Hausunterricht), tendo em vista a ocupação dos membros da família no trabalho do desbravamento e cultivo. Outra forma de ensino, também precário, consistia em reunir as crianças de uma mesma linha na casa de um colono mais instruído que se encarregava da alfabetização. Depois surgiram as Gemeinde Schule - escolas comunitárias mantidas pelos colonos, e muitas vezes o professor era ele próprio um colono/agricultor. Eram pessoas respeitadas nas comunidades e, eventualmente, assumiam algumas funções religiosas na ausência de padres e pastores evangélicos luteranos.

As escolas comunitárias, porém, tiveram maior importância nas primeiras décadas da colonização, e ao longo da segunda metade do século XIX foram perdendo espaço para as escolas mantidas por ordens religiosas católicas e pela igreja evangélica luterana. A relevância, inclusive numérica, dessas organizações de ensino particular, que funcionavam como rede, é inegável. No entanto, ao iniciar-se o debate sobre a nacionalização do ensino após a Primeira Guerra Mundial, houve um maior investimento do Estado nas escolas públicas, procuradas principalmente pela parcela menos abonada da população urbana e rural, apesar das considerações mais ou menos etnocêntricas acerca da superioridade e da eficiência do ensino em língua alemã, observadas em depoimentos e nas publicações periódicas teuto-brasileiras (cf. Seyferth 1982).

Isto deixa claro o ponto problemático da socialização escolar, evidenciada no discurso assimilacionista brasileiro: mesmo com a maior oferta de escolas públicas, com aulas ministradas em português, a escola alemã era considerada superior em termos de eficiência pedagógica e transmissão de conhecimento. Também era reivindicado o ensino da língua alemã como uma disciplina ao lado do português, refletindo o discurso básico da etnicidade teuto-brasileira. De fato, havia o temor da perda da língua materna ensinada na socialização primária, porém este tipo de reivindicação nunca foi atendido. Por outro lado, prevaleceu nas representações a noção de legitimidade do modelo escolar, advinda do fato de os imigrantes terem sido "deixados entregues à própria sorte" nos tempos pioneiros e, por esta razão, precisaram tomar providências para dar aos filhos pelo menos a educação básica (Willems 1946; Seyferth 1982).

À parte suas motivações práticas, nas áreas coloniais e nas cidades onde se estabeleceram imigrantes alemães surgiu um sistema escolar teuto-brasileiro (cf. Willems 1946; Seyferth 1982; Dalbey 1970; Kreutz 1994), apesar do uso mais frequente da expressão "escola alemã". Havia uma diferenciação entre as escolas (assinalada por Willems 1946, cap. XII), 
particularmente entre aquelas situadas nas comunidades rurais (linhas) e as mantidas por entidades religiosas, especialmente nas cidades. No entanto, entre elas circulavam publicações (em alemão) destinadas aos professores, havia produção de material didático no âmbito local, mas também originário na Alemanha; muitos professores eram alemães natos, emigrados para esta finalidade; padres e freiras de diferentes ordens católicas, assim como pastores evangélicos, originários da Alemanha, atuavam como professores nas escolas confessionais.

Entre as publicações mais relevantes destacava-se o Allgemeine Lehrerzeitung für Rio Grande do Sul; mas a questão escolar também era discutida na imprensa teuto-brasileira e nos Kalender (publicações anuais); os professores reuniam-se em congressos. Nas primeiras décadas do século XX (até o momento da nacionalização) estavam em atividades conjuntas diversas associações, destacando-se a Deutsche Schulverein, e suas congêneres estaduais, articuladas com a Allgemeine Deutsche Schulverein (sediada na Alemanha), e as associações de professores, com destaque para a Verein Deutschbrasilianischer Privatichrer, e suas ramificações regionais. Segundo Fouquet (1974:172), existiam seis associações regionais de professores que promoviam reuniões a fim de estudar e resolver os problemas comuns, e elas fundiram-se na Associação Nacional dos Professores Teuto-brasileiros, com sede em São Paulo, depois da Primeira Guerra Mundial, quando foi imposto o ensino bilíngue.

A menção às publicações e às associações, ainda que pontual, mostra o grau de organização desse sistema escolar (com seu formato de rede) voltado para uma teuto-brasilidade que estava sendo objeto de crítica do nacionalismo republicano desde o final do século XIX. A razão disto é óbvia e vai além da destacada necessidade de educar os filhos dos colonos: tratava-se de garantir a socialização (étnica) iniciada no lar dentro dos parâmetros da germanidade, e a continuidade do aprendizado (agora formal) da língua materna que vicejou no cotidiano das regiões coloniais e nos meios urbanos onde era mais visível a presença de imigrantes e descendentes.

\section{IV}

Num trabalho sobre a colonização alemã em Santa Catarina, publicado em 1917, Manoel Duarte manifestou sua preocupação com a situação escolar, informando que nas escolas elementares do "populoso" município de Blumenau o ensino da língua portuguesa era "deplorável", pois existiam apenas um grupo escolar e nove escolas isoladas públicas, portanto, mantidas 
pelo Estado. Ali estava implícita certa crítica à política educacional, diante da absoluta predominância das 123 escolas alemãs do referido município, na maioria das quais o vernáculo não constava do currículo. Este era o ponto essencial dos debates sobre a questão escolar naquele momento marcado pelos acontecimentos da Primeira Guerra Mundial, que exacerbaram o patriotismo e o nativismo .

A situação de guerra com a Alemanha, formalizada em 1917, e a temporária intervenção nas escolas alemãs revelam a vinculação da escola e da língua com o princípio da nacionalidade ${ }^{10}$ e seu corolário, o patriotismo. Entre outras coisas, o ensino da língua alemã foi proibido, as aulas deviam ser ministradas em português, e a educação cívica, a adoção de livros de autores brasileiros e do hinário patriótico tornaram-se obrigatórios. Muitas escolas deixaram de funcionar, prejudicando o atendimento da demanda não absorvida pelas insuficientes escolas públicas, razão provável do afrouxamento das medidas nacionalizadoras em 1919. O desabafo de Duarte (1917), as observações de Willems (1946), e até mesmo as reflexões de importantes mentores da campanha de nacionalização do Estado Novo (por exemplo, Câmara 1940; Couto 1941a; Neiva 1944) vão no sentido de reconhecer a insuficiência e a inadequação das escolas públicas, e a consequente dificuldade de atender à demanda de filhos e netos de imigrantes.

De fato, os integrantes do Conselho de Imigração e Colonização do Estado Novo (1937-1945) também consideravam a expansão do ensino publico de qualidade tão importante quanto a extinção das escolas de perfil étnico:

Nas zonas desnacionalizadas, para suplantar os educadores estrangeiros e as escolas particulares difíceis de serem suplantadas, são precisas escolas e mais escolas, bem aparelhadas e entregues a professores aptos, para que as forças de reação à campanha nacionalizadora não possam mais afirmar que o Brasil deseja nivelar pela quota mais baixa (Neiva 1944:560-561, grifos do autor).

Na avaliação comparativa, Lourival Câmara (1940:706) é mais contundente e jocoso, referindo-se à rejeição da escola nacional, "bem menos organizada, com professorinhas que não inspiravam confiança", despreparadas para ensinar aos filhos e netos de imigrantes. Segundo seus termos, “a escola alemã era [...] bem instalada, confortável [...] risonha e franca, em contraste com a nacional sem conforto nem pedagogia". Os dois autores citados expõem uma situação mais geral, pois escolas comunitárias com ensino em outra língua eram mantidas por outros grupos de imigrantes e descendentes (caso de italianos, libaneses, japoneses etc.), também atingidas pelas medidas nacionalizadoras. Contudo, a escola alemã era considerada a expressão maior do "enquistamento étnico", inclusive por sua representatividade numérica. 
A retórica da incúria dos governos anteriores, acusados de permitir o isolamento dos núcleos estrangeiros, porém, não atenuou o ímpeto intervencionista dos nacionalizadores:

As frases candentes com que o Excelentíssimo Presidente da República estigmatizou a imperdoável negligência dos governos do Império e da Primeira República, no seu discurso de Blumenau [...] merecem ser aqui citadas em apoio à nossa tese: a culpa da lamentável demora na assimilação integral dessas populações não lhes cabe, mas principalmente ao abandono em que foram deixadas pelos governos (Câmara \& Neiva 1941:98).

A repetição do argumento presidencial anteriormente mencionado apenas introduziu uma variável que redimia simbolicamente o apego à distintividade étnica - forma de convencimento dos "alienígenas" que resistiam ao "abrasileiramento", permanecendo, segundo os autores citados, "à margem da civilização do resto do país", organizados como "verdadeiros quistos raciais, psicológicos, linguísticos, culturais e sociais". Daí a imposição das medidas nacionalizadoras, entre as quais se destaca a intervenção nas escolas étnicas em nome da "consciência brasileira" e dos "imperativos de segurança nacional" (Cf. Câmara \& Neiva 1941:93, 96, 98).

O passado de negligência do Estado em relação ao ensino público aparece nas considerações de Willems sobre a assimilação. Seu primeiro livro sobre a imigração alemã, publicado em 1940, foi sistematicamente citado e interpretado (às vezes de forma errônea) ${ }^{11}$ nos escritos de membros do Conselho de Imigração e Colonização. Não à toa, o livro mencionado foi considerado importante fonte de informações para subsidiar a nacionalização pois, segundo Couto (1941b:789), mostra que as colônias estrangeiras "adquiriram, pela densidade dos seus elementos étnicos uniformes e compactos, uma certa cor de perigo social". Analisando a questão escolar, Willems foi taxativo, tendo assinalado tanto a necessidade do aprendizado da língua vernácula quanto a negligência governamental ao não providenciar escolas públicas suficientes. Em seus termos, se isto tivesse ocorrido, a língua alemã teria desaparecido na segunda geração. E completa: "Isso não se deu. Ao contrário, filhos e netos dos primeiros imigrantes raramente chegaram a conhecer o vernáculo" (Willems 1946:385).

É difícil aceitar o vaticínio do desaparecimento da língua materna, pois se trata de uma suposição referida ao poder de assimilação da sociedade nacional que recebe imigrantes. ${ }^{12}$ O próprio Willems $(1940,1946)$ reconheceu a importância da língua alemã no cotidiano, afirmando seu valor utilitário e simbólico. 
[...] à medida que as comunidades vão tomando feições mais definidas, as suas instituições, sobretudo igreja e escola, fazem da transmissão da língua um culto. Ela vem a simbolizar valores étnicos, religiosos e, mais recentemente, também políticos (Willems 1946:386).

O foco de Willems não era a etnicidade, apesar do realce dado às diferenças culturais que configuravam uma teuto-brasilidade indicativa da pertença étnica. A vinculação igreja-escola nesse contexto certamente deu subsídios aos nacionalizadores, pois já estava delineada no livro anterior (Willems 1940) e objetivada nas estatísticas escolares.

Nesse sentido, a questão escolar era prioritária (debatida, sem efeitos práticos, desde o início da República), inclusive por sua associação com o patriotismo e a consciência nacional. Para o nacionalismo exacerbado pela xenofobia, desconhecer a língua vernácula e privilegiar currículos que não se coadunavam com as normas do Ministério da Educação não eram apenas um indicador multicultural, pois representavam a desqualificação, como alienígenas, estrangeiros, de imigrantes e descendentes.

A desqualificação pode ser observada num texto de Lourival Câmara (1940), cujo título é por si mesmo significativo pela generalização que contém: "Estrangeiros em Santa Catarina". Segundo sua avaliação, "estrangeiro de direito" é aquele que não possui a nacionalidade brasileira, um não cidadão; mas faz questão de mencionar os "estrangeiros de fato", nascidos no Brasil, que falam um idioma estrangeiro no cotidiano. Neste caso, o referencial são os imigrantes e descendentes que valorizam sua distintividade cultural, recusando o abrasileiramento.

O uso sistemático das categorias estrangeiro e alienígena, aplicadas inclusive aos descendentes nascidos no Brasil pelos encarregados da política imigratória e da nacionalização, tem caráter de estigma e supõe a ausência de brasilidade, de patriotismo e a negação do espírito nacional. Elas não são apenas indicativas do distanciamento cultural, ou de ausência de assimilação, porque desqualificam cidadãos legítimos em nome da unidade nacional, que deve ser perpetuada principalmente através da escola e da língua vernácula.

O papel fundamental atribuído à educação escolar e à língua vernácula na conformação da consciência nacional e, por extensão, do patriotismo tem sido assinalado pelos estudiosos do nacionalismo (cf. Gellner 1983; Hobsbawm 1990; Guibernau 1997). No entanto, os mesmos princípios de natureza ideológica que nortearam o ideal da nacionalidade estão presentes no discurso étnico teuto-brasileiro sobre a escola e a língua materna, intensificado depois da Primeira Guerra Mundial, num claro confronto entre 
nacionalismo e etnicidade evidenciado nos escritos dos nacionalizadores e nos atos legais que regularam a nacionalização do ensino em 1937, e em matérias de jornais e almanaques publicados em língua alemã que circularam até 1939 produzidas por imigrantes e descendentes.

Num capítulo em que trata da "ambivalência das atitudes" de imigrantes e descendentes, Willems (1940:128-166) transcreve longos trechos de matérias do jornal Der Kompass, editado em Curitiba, que denotam principalmente a pertença étnica reivindicada como legítima e a cidadania num Estado com população heterogênea, assinalando a dupla condição de alemães e brasileiros. Para Willems, a ambivalência era um indicador do processo de assimilação de um grupo marginal (ainda não integrado à nova sociedade). Mas as matérias citadas contêm a principal reivindicação em pauta nas décadas de 1920 e 1930, isto é, o (suposto) direito de formar uma comunidade étnica dentro do Estado brasileiro, resumido em duas frases contidas num artigo assinado por L. B. Doetzer Jr., publicado no Der Kompass $\left(\mathrm{n}^{\circ} 8\right.$, 1938): "A etnia conhece costumes, usos e a língua. Cultivam-se os valores étnicos sem prejuízo de sua "brasilidade" [...] Nós somos um grupo étnico dentro da comunidade brasileira" (apud Willems 1940:147).

A citação tem um significado preciso: Deutschtum e brasilidade podem ser conciliados, e a teuto-brasilidade é indicadora da integração de imigrantes e descendentes ciosos da sua pertença étnica demarcada pela Muttersprache (língua materna) e as tradições culturais. E tais coisas se aprendem no lar, na escola. Willems (1946:414-415) afirmou que através da escola "se fizeram tentativas de perpetuar a lealdade dos colonos em relação a determinados valores da cultura original", mas também se refere a livros didáticos nos quais é dito que a pátria é o Brasil, reafirmando, porém, que a língua materna é o alemão aprendido dos pais.

A ênfase na identidade étnica reportada à escola alemã e seu papel na transmissão dos valores e da cultura germânica estão presentes nas publicações teuto-brasileiras desde o final do século XIX, num posicionamento crítico em relação às ideias de nação racial e culturalmente homogênea do nacionalismo republicano. Nesse contexto, a questão da língua materna é o assunto prioritário nos debates sobre o ensino básico, apesar das muitas referências ao descaso do Estado que motivou a criação de um sistema escolar teuto-brasileiro e àquelas da necessidade do bilinguismo, assinalada, por exemplo, numa matéria reproduzida em vários jornais em 1887. Nela, afirma-se que imigrantes e descendentes "não querem ser mudos na sua nova pátria", sendo, pois, necessário aprender a língua portuguesa, mas não são negligentes "a ponto de deixar[em] sua própria e magnífica língua [...] esta língua cultural de tão grande e bela memória que será para a índole da 
raça sempre a única adequada". No texto está implícita a reivindicação de uma autonomia linguística e cultural e a ênfase no compromisso patriótico como cidadãos brasileiros. ${ }^{13}$

Tal compromisso é recorrente nas publicações periódicas em língua alemã, inclusive na forma poética, como se observa, por exemplo, na matéria "Deutscher Sang und Brasilianischer Patriotisms", publicada no jornal Der Urwaldsbote, de Blumenau. Nela, o editorial elogia duas coletâneas de Lieder (canções) destinadas às escolas, expressando "o patriotismo teuto-brasileiro" contido no termo dualista Deutschbrasilianertum, "cantando a beleza e a magnificência do Brasil [...] um patriotismo que brota do coração". Nessa contextura, as escolas alemãs, "atacadas pelos nativistas", são defendidas porque "o patriotismo brasileiro não precisa ser cultivado apenas na língua portuguesa". Significativamente, são incluídos no texto dois poemas que falam das belezas da "nova pátria", um deles fazendo a vinculação da pátria com o lar, uma figura de retórica própria do nacionalismo romântico na configuração da ideia de nação alemã. ${ }^{14}$

O editor do jornal, Eugen Fouquet (um imigrante naturalizado), era considerado defensor intransigente do germanismo por seus desafetos brasileiros no campo político estadual, pois afirmava que o Brasil tinha população bastante diversificada, com muitos imigrantes de diferentes nacionalidades e, por isso, não podia ser uma nação unívoca. Segundo seus termos, isto dava legitimidade à escola alemã e ao ensino da língua materna, cuja conservação "deve ser mantida como a verdade mais importante [...] dominar no lar, primar na escola e participar equitativamente da vida pública". Contudo, destacou a necessidade do bilinguismo. ${ }^{15}$

A partir da década de 1920 ocorreu o recrudescimento do discurso étnico envolvendo a questão escolar, diante das evidências da nacionalização do ensino que vinha sendo implementada no estado de São Paulo. Nesse período, o tema predominante é a utilidade prática do ensino bilíngue e, nesse sentido, o artigo "Die nationalisierung", publicado por Paul Aldinger no jornal Blumenauer Zeitung, é exemplar. Ali, ele critica uma fala do presidente da República, Epitácio Pessoa, sobre a necessidade de o ensino ser feito exclusivamente na língua vernácula. Aldinger, um autor conhecido nos meios teuto-brasileiros, afirma que o presidente estava errado, pois as escolas privadas não ensinam apenas uma língua estrangeira, o português já estando incluído no currículo - referência ao aprendizado bilíngue vigente depois da guerra. Conclui sua argumentação com uma frase do governador Hercílio Luz (de Santa Catarina): "quem conhece duas línguas está melhor do que quem compreende apenas uma", plataforma de um "patriotismo prático" e solução melhor para o problema escolar. ${ }^{16}$ 
Este é um discurso repetido, crítico em relação ao nativismo dos brasileiros, observado também nos anuários (Kalender) e em textos de autores teuto-brasileiros sobre a colonização. Mas o ensino bilíngue aparece mais como um adendo necessário à cidadania (aí compreendidas a integração social e a política na "nova pátria"). Nesse sentido, o artigo de T. F. Niederhut, intitulado "Die Deutschbrasilianische Landschule", publicado no Kalender für die Deutschen in Brasilien, em 1920, ${ }^{17}$ é bastante elucidativo. Segundo o autor, a escola não existe apenas para que as crianças aprendam a língua alemã, mas também para conhecer e incorporar as boas qualidades alemã, o espírito e a prática do Deutschtum. Nela, as crianças aprendem corretamente a língua portuguesa, mas isto não representa perigo para a germanidade, pois é necessário desempenhar um papel de cooperação e competência no país. Assim, está implícito neste e em muitos outros textos que a língua vernácula é necessária diante dos deveres e dos direitos da cidadania, mas a língua materna deve prevalecer no lar, na comunidade e na escola. Uma manifestação contundente dessas premissas pode ser observada numa outra matéria que conclama a luta contra a opressão da língua alemã na vida privada, na escola e nas associações, e afirma o direito de manter escolas privadas e a necessidade do aprendizado (utilitário) da língua portuguesa. ${ }^{18}$

O discurso sobre a legitimidade da escola alemã (com ensino bilíngue) e do uso cotidiano da língua materna ficou mais acirrado na década de 1930 por dois motivos: a nacionalização, que se afigurava muito mais ampla do que a intervenção nas escolas de perfil étnico, e a propaganda nazista, radicalizando a pertença nacional por critérios raciais, com repercussão em algumas publicações periódicas e escolas, mas também criticada por seu conteúdo doutrinário de subserviência partidária e racismo.

Não obstante os posicionamentos ambíguos em relação ao nazismo, o elemento de discordância era o qualificador étnico teuto-brasileiro não reconhecido pelos nazistas, que procuravam impor a identidade de Auslanddeutsche (alemães que vivem no estrangeiro) pertencendo a uma Volksgemeinschaft (comunidade nacional) fundamentada na raça e no sangue comuns (cf. Seyferth 1982).

O ideário nazista de Blut und Boden (sangue e terra) e suas implicações de pertença à "raça ariana (pura)" foram contestados em várias publicações e, para muitos autores que divulgaram seu pensamento nos jornais e nos anuários, a língua é o elemento fundamental da pertença à nação alemã, e fatores biológicos têm pouca importância na configuração do Deutschtum. Um dos muitos exemplos desta posição está no artigo "Rasse, Sprache, Volkstum", no qual o autor relativiza a noção de "sangue ariano", recorrendo aos escritos de figuras exponenciais do nacionalismo romântico alemão - no caso, Herder, Fichte e Humboldt - atribuindo à língua um papel preponderante como indicador do Volkstum. ${ }^{19}$ 
A síntese perfeita da crítica parcial ao discurso e às ações de membros do NSDAP (Partido Nacional Socialista dos Trabalhadores Alemães) está contida numa matéria do Kalender für die Deutschen in Brasilien, que supõe o diálogo do editor com pessoas de diferentes profissões. ${ }^{20}$ Ali se afirma que nenhum teuto-brasileiro tem a intenção de transplantar o nacional-socialismo para o Brasil, reafirmando a teuto-brasilidade desqualificada no discurso nazista sobre pertencimento nacional. Não obstante, o partido é elogiado por ter assentado a Alemanha entre as grandes nações do mundo, promovendo seu desenvolvimento; por outro lado, são mencionados os "abusos" dos grupos locais (Ortsgruppen) do NSDAP, que parecem desconhecer a "realidade local". O conflito de interpretações acerca do Deutschtum e sua dimensão prática atacada pelos nazistas ficam claros quando é dito que imigrantes e descendentes souberam manter "as realizações culturais que satisfazem o germanismo no estrangeiro, como escolas, igrejas, hospitais, cooperativas, livrarias e associações alemães, jornais [...] já existentes antes dos grupos do NSDAP", mas sua pátria (em sentido amplo, político) é o Brasil. ${ }^{21}$ Para o nazismo, a germanidade teuto-brasileira não era suficiente para qualificá-los como alemães aceitáveis na nova ordem partidária.

Nesse contexto de discussão sobressaem dois assuntos destacados naquela matéria: a questão escolar e a comunidade étnica teuto-brasileira diante da ameaça de nacionalização discutida pelo governo de Getúlio Vargas. O plano de nacionalização das escolas privadas é mencionado como "um grande perigo" para a comunidade étnica, porque o ensino será ministrado apenas na língua portuguesa. Aí se defende a permanência do ensino étnico, argumentando-se que o governo poupou muito dinheiro porque as escolas alemães realizaram uma tarefa que cabia ao Estado; e lembrando que nelas já estavam sendo ensinadas a língua portuguesa, a geografia e a história do Brasil, além dos cantos patrióticos e o amor pela pátria brasileira. Resumindo, ensina-se aos alunos serem bons cidadãos e, nesse sentido, é melhor para o Brasil que teuto-brasileiros mantenham sua germanidade, "fonte de força dos imigrantes que fazem o bem para sua pátria, o Brasil".

No entanto, queixa-se o editor, os bons cidadãos descendentes dos alemães são considerados "brasileiros de segunda classe em relação aos lusos" - mostrando o outro lado do conflito caracterizado pela intenção nacionalizadora do abrasileiramento que estigmatizou as diferenças étnicas e culturais. Aliás, o texto termina com uma comparação de senso comum no discurso étnico: se os "lusos" se orgulham dos bandeirantes e da sua ligação com Portugal, os teuto-brasileiros se orgulham dos seus antepassados que, na selva, construíram colônias, comércio, indústrias etc., num leal trabalho cooperativo pelo engrandecimento do Brasil que prosseguiu com os descendentes. 
O debate sobre a escola (incluída entre as instituições étnicas) traz à baila a socialização valorizando o binômio Haus und Schule (lar e escola) nos mesmos termos: cuidar da preservação do Deutschtum é a melhor forma de contribuir para o desenvolvimento econômico e o engrandecimento da nova pátria. A premissa da socialização étnica contida no binômio foi bastante enfatizada na década de 1930, inclusive em folhetos comemorativos, assinalando um "trabalho conjunto essencial à formação dos jovens", inculcando neles "a particularidade da alma (Seele) alemã", pois mantinha a escola ligada à casa (família) dos pais. ${ }^{22}$

Os nacionalizadores mais radicais, na sua xenofobia, alertavam para a necessidade de interferir diretamente no lar alienígena, apesar de reconhecerem as dificuldades inerentes a essa forma de opressão. ${ }^{23} \mathrm{~A}$ intromissão mais direta no espaço doméstico (lar) não aconteceu, mas a questão da socialização escolar tornou-se prioritária também por causa da ação nazista em algumas escolas (especialmente as localizadas em áreas urbanas), através da propaganda, ou de professores alemães natos vinculados aos grupos locais do partido, motivo adicional para o rigor do "abrasileiramento" relacionado à imigração alemã. Obviamente isto não deve ser generalizado, porém a presença transnacional promovida por um partido político estrangeiro estava sendo amplamente criticada e reprimida, embora tolerada pelo governo Vargas antes de 1939.

De acordo com Câmara e Neiva, o lar é o lugar seguro da conservação de usos e costumes alienígenas, e principal obstáculo da campanha de nacionalização, difícil de ser atingido, porém é possível utilizar a "influência retroatora da criança sobre os pais" através da escola: "Se o lar, pela sua ação constante e insubstituível, é o primeiro fator de amoldamento da criança à sociedade, a escola é o segundo degrau desse processo formativo do caráter" (Câmara \& Neiva 1941:100).

Nesta perspectiva, se o governo não chega diretamente ao lar, pode interferir dando a orientação nacionalizadora na escola. Não havendo controle total sobre o binômio lar-escola, cabia impor moral, civismo e princípios assimilacionistas em âmbito escolar, e esta premissa orientou a prática intervencionista. Nesse sentido, as principais medidas que orientaram a transição são indicadoras do ideal de univocidade do Estado-nação. As escolas tinham a obrigação de difundir o patriotismo e a consciência nacional através de uma disciplina específica voltada para a educação cívica e moral, manter a bandeira brasileira em destaque, participar de desfiles cívicos, ensinar cantos patrióticos, músicas brasileiras etc. ${ }^{24}$ Além disso, o corpo docente devia ser formado por brasileiros natos, graduados em instituições brasileiras; as aulas só podiam ser ministradas em língua portuguesa; o ensino de língua estran- 
geira para menores de 14 anos foi proibido; os livros didáticos passaram a ser censurados pelo Ministério da Educação; e as escolas nacionalizadas não podiam receber subvenções de instituições e governos estrangeiros.

Muitas escolas teuto-brasileiras, especialmente aquelas localizadas em centros urbanos, adaptaram-se às novas regulações do ensino, com algumas dificuldades e certamente sob protestos; outras encerraram suas atividades. As medidas motivaram o ensino clandestino (em língua alemã) em algumas áreas coloniais - situação temporária logo reprimida. Essa forma de resistência é mencionada por Dalbey (1970) e por várias pessoas que vivenciaram a transição, entrevistadas por mim no Vale do Itajaí durante uma pesquisa realizada na década de 1980 .

Conforme observação de Gellner (1983), o nacionalismo engendra a nação, e o Estado usa seletivamente a cultura (supostamente compartilhada) como repositório natural da legitimidade política e fundamento da identidade nacional. Assim, arbítrio e cultura formam a base da concepção de nacionalidade. A língua vernácula, por sua vez, é o outro elemento da univocidade por ser o veículo primordial da comunicação. Daí a ênfase na escola como o lugar da configuração da consciência nacional, sob controle do Estado, modo de desenvolver sentimentos patrióticos. Referindo-se à língua vernácula, Guibernau (1997:80), a partir do exemplo francês, afirmou que "o poder do Estado de impor uma língua e expandi-la por meio de um sistema escolar era a chave para iniciar a morte lenta das línguas e dos dialetos minoritários".

A intervenção nacionalizadora que cerceou as instituições comunitárias étnicas e extinguiu a rede escolar teuto-brasileira tinha este propósito de impor a língua vernácula e uma cultura luso-brasileira supostamente hegemônica, num imaginado processo de formação nacional de fundamento assimilacionista, que exigia o apagamento dos "ideais alienígenas" e dos "ambientes antinacionais" produzidos pela imigração em geral, ${ }^{25}$ embora os alemães e os descendentes fossem considerados etnicamente enquistados. O contraditório nesse contexto conflituoso de nacionalismo exacerbado é o surgimento da etnicidade teuto-brasileira igualmente baseada na diferença cultural e linguística, em habitus (cf. Weber 1991) e no papel da escola e do lar na socialização (étnica) primária, produzindo uma identidade discrepante do ideal de pertencimento nacional.

O impacto nacionalizador atenuou-se depois do regime ditatorial do Estado Novo, mas manteve-se a crença na assimilação dos alienígenas como um princípio unificador da nação, presente no Decreto-lei 7.967, de 18/09/1945 - a lei de estrangeiros que vigorou nas décadas seguintes. A constância discursiva sobre o papel da educação na assimilação dos imigrantes pode ser exemplificada pelo artigo de D'Aragão (1946). Ali, a autora sugere 
algumas medidas idênticas às levadas a cabo no processo de nacionalização forçada: ensino ministrado na língua vernácula; preparo cívico para a nacionalização; participação em atos comemorativos cívicos; ensino das tradições (e história) brasileiras; círculos de estudos que identifiquem o estrangeiro com o nacional etc. No entanto, deve-se assinalar a discrepância entre ideologia e práticas nacionalizadoras, corroborada pela longa duração dos debates sobre assimilação desde meados do século XIX, em contraste com a tolerância do Estado em relação às escolas particulares com perfil étnico até 1937, em parte derivada da carência de escolas públicas. No caso da imigração pós-guerra, apesar da ênfase na questão educacional acima referida, os imigrantes não foram atingidos pela campanha de nacionalização.

Os poucos dados apresentados mostram que a "escola alemã" estava incluída na estrutura da organização comunitária étnica como um dos (muitos) veículos do germanismo. Fica evidente aí uma questão central do nacionalismo desde o século XIX, relacionada ao perfil idealizado do Estado-nação: o papel da escola na formação dos cidadãos nacionais, o que presume uma socialização cívica patriótica. A própria existência da língua vernácula é considerada essencial para cimentar a univocidade do Estado e a singularidade da nação. Tal forma de particularismo não exclui a percepção territorial e política do Estado-nação, mas existe a crença na história compartilhada que moldou a pátria e na comunidade de língua e cultura, além de outros indicadores associados a habitus e sentimentos comuns, conforme assinalou Max Weber (1991:275).

No caso brasileiro, o princípio da identidade nacional baseado na língua vernácula e numa imponderável brasilidade recrudesceu na virada para o século XX, quando ficaram mais visíveis as especificidades culturais produzidas pela imigração, ensejando um discurso assimilacionista xenófobo. As lideranças teuto-brasileiras, por sua vez, defenderam, através de publicações, um Estado cultural e linguisticamente plural, às vezes de forma etnocêntrica, numa demonstração de etnicidade que contrariava aquele princípio de nacionalidade, dando ênfase a uma identidade de dupla pertença (à nação alemã e ao Estado brasileiro). A palavra-chave desse discurso era Deutschtum (germanidade), associada a uma ideia particularista de Heimat (pátria) estendida para o Brasil e caracterizada pela peculiaridade germânica observada no uso cotidiano da língua materna, na paisagem cultural diferenciada, urbana ou rural, construída pelos imigrantes que trouxeram 
a civilização e o progresso, os costumes e os hábitos, e sentimentos de pertença a uma nação alemã que podia ser territorializada em qualquer lugar. Heimat é um termo referenciado ao lar, uma pátria recôndita, sem um sentido político, configurando a "comunidade étnica". Daí a ênfase maior na identidade étnica e seus indicadores mais precisamente vinculados à socialização: a família e a escola.

O pertencimento étnico contido nas representações da germanidade e da pátria "construída" pelos imigrantes (a primeira geração) põe em evidência a etnicidade, conceito que na teoria antropológica refere-se à diferenciação cultural e às suas implicações na interação social, nas práticas cotidianas e nos usos de uma identidade étnica (coletiva, individual) e em seus marcadores simbólicos (cf. Eriksen 1991; Jenkins 1997) que, no caso de contextos imigratórios, por estarem em consonância com a nacionalidade de origem, entram em conflito com a nacionalidade dominante no país de acolhida.

Na situação difícil criada pelo confronto entre o pluralismo cultural e linguístico teuto-brasileiro e a nação unívoca luso-brasileira configurada na República, o ensino particular em língua alemã passou a ser questionado como um risco à segurança nacional, percebido como mais um indicador do "perigo alemão" (ver nota 8), tendo em vista a grade curricular e o material didático de inspiração alemã usados nas escolas. A propaganda pan-germanista da Alldeutsche Verband (até 1914) e a influência nazista na década de 1930, observada em algumas escolas, amplamente denunciadas, reforçaram os argumentos mais radicais em prol da nacionalização do ensino, concretizada no Estado Novo (1937-1945).

De fato, a língua, mais do que uma contingência da comunicação e da interação social, entrou na esfera dos valores subjacentes à pertença étnica e nacional. Ela é o fundamento maior da diferença cultural, situada pelos atores sociais na dimensão primordial. Esta crença está presente nas representações teuto-brasileiras sobre a "escola alemã" amplamente defendida como um "direito" à diferença ${ }^{26}$ até o momento crítico da nacionalização do ensino. 
Recebido em 21 de novembro de 2017

Aprovado em 21 de novembro de 2017

Giralda Seyferth era professora colaboradora do Programa de Pós-Graduação em Antropologia Social, Museu Nacional, Universidade Federal do Rio de Janeiro, Rio de Janeiro/RJ, Brasil.

\section{Notas}

* A versão resumida deste trabalho - "Socialization and ethnicity: the german-brazilian educational issue" - foi apresentada no Workshop "Reception, Integration and Socialization of Immigrants", na International Metropolis Conference - Migration, Milão, Itália, 3 a 7/11/2014.

1 Estudiosos como Willems (1946) e Fouquet (1974) preferiram um indicador linguístico para dimensionar estatisticamente a imigração alemã, dada a relevância das entradas de grupos identificados como deutschstämmig (de origem alemã), provenientes da Áustria, da Rússia e de outros países do Leste europeu. A estimativa citada é de Fouquet (1974:17).

2 Apesar do empenho para atrair a imigração espontânea de europeus (e, no início, particularmente de alemães), isto não ocorreu, prevalecendo no século XIX a ação de aliciadores a serviço do governo e o direcionamento para áreas coloniais. Processo semelhante ocorreu em São Paulo, onde a imigração dirigida destinava-se sobretudo à substituição do braço escravo na plantation cafeeira.

3 Este dado justifica a periodização aqui adotada - 1850-1937 - pois a expansão das colônias foi objeto de crítica do nacionalismo, e o ano de 1937 marca o início da nacionalização do ensino implementada pelo Estado Novo.

4 Essa dimensão estatística corresponde à maior concentração de imigrantes alemães e descendentes no Rio Grande do Sul e em Santa Catarina no período histórico mencionado (as décadas de 1920 e 1930). Willems (1940:292; 1946:405-407) reproduziu tabelas publicadas no Allgemeine Lehrerzeitung für Rio Grande do Sul (junho, julho, 1930), um jornal destinado aos professores, e por Porzelt (1937).

5 O impacto da intervenção nacionalizadora pode ser exemplificado pelo fechamento de 200 escolas das regiões coloniais alemãs em Santa Catarina, através do Decreto 88, de 31.03.1938, resultante de um "imperativo político" - a segurança nacional - conforme assinalaram Câmara e Neiva (1941: 92).

6 Ver, por exemplo, os trabalhos de Câmara (1940), Câmara e Neiva (1941) e Couto (1941a e b), publicados na revista editada pelo Conselho de Imigração e Colonização, órgão responsável pela política de nacionalização. 
7 Nos aspectos pedagógicos, a grade curricular e os livros didáticos foram analisados por Rambo (1994) e Kreutz (1994), no Rio Grande do Sul, e por Blogoslawski (2002) e Wiederkehr (2014), em Santa Catarina.

8 A expressão tem vários significados, mas o elemento preponderante, usado para condenar a diferença étnica, era a presunção de uma intenção separatista que podia resultar na secessão de uma parte do Rio Grande do Sul e Santa Catarina com o beneplácito do Estado alemão. Sobre este assunto, ver Seyferth (1982) e Geertz (1991).

9 Os primeiros professores que atuaram nessas escolas públicas eram estrangeiros, e as aulas ministradas na língua alemã. Mas com a criação mais formal de grupos escolares e escolas rurais isoladas, o ensino público passou a ser ministrado na língua portuguesa por professores brasileiros.

10 Segundo Hobsbawm (1990:126, 146), esse princípio é denotativo da identificação da nação com o Estado, e prevaleceu na formalização dos tratados de paz após a Primeira Guerra Mundial, em grande parte alimentado pelo critério etnolinguístico.

11 Numa interpretação sociológica baseada nos conceitos de assimilação e aculturação, Willems $(1940,1946)$ analisou os indicadores da mudança sociocultural, ainda em curso, nas áreas ocupadas por imigrantes alemães e descendentes, mas destacando igualmente as características da "cultura híbrida teuto-brasileira" (Willems 1946:574). Num trabalho posterior (Willems 1951:209) afirma que seu entendimento sobre esses processos de transformação social nada têm a ver com a assimilação entendida pelos brasileiros, erroneamente confundida com "abrasileiramento", inclusive na sua dimensão biológica de miscigenação.

12 Num verbete sobre assimilação, Park (1937) alertou para as dificuldades do uso desse conceito na análise sociológica da imigração, pois envolve processos sociais em contínua transformação.

13 Blumenauer Zeitung, Blumenau (SC), ano 7, n. 15:01, 09/04/1887. A matéria intitulada "Brasilien und die Deutschen" critica o assimilacionismo brasileiro e foi originalmente publicada no jornal Germania, de São Paulo, fato que aponta para uma circulação de ideias relacionadas ao pertencimento à nação alemã. As referências completas das matérias publicadas nos jornais e nos anuários - fontes primárias estão indicadas nas notas de rodapé.

14 Der Urwaldsbote, Blumenau (SC), ano 15, n. 44: 01, 30/11/1907. Sobre os significados étnicos da poesia teuto-brasileira, ver Seyferth (2004).

15 Der Urwaldsbote, Blumenau (SC), ano 9, n. 31:01, 01/02/1902. O uso da língua alemã na vida pública incluía o espaço das reuniões políticas formais de partidos e câmaras de vereadores - coisa impensável para o nacionalismo brasileiro.

16 Blumenau Zeitung, Blumenau, ano 40, n. 49:01, 27/06/1921. A referência de Aldinger são as escolas mantidas por diferentes imigrantes e descendentes, defendendo o ensino bilíngue - forma de contornar as exigências de enquadramento nas normas do Ministério da Educação. 
17 O Kalender für die Deutschen in Brasilien foi o mais importante (e popular) anuário teuto-brasileiro, fundado em São Leopoldo (RS) pelo pastor Wilhelm Rotermund, que mantinha uma editora. Assim como os jornais, este tipo de publicação anual divulgava o ideal de teuto-brasilidade e também a literatura em língua alemã (contos, poesias, novelas) produzida no Brasil.

18 A matéria, intitulada "Das Brasilianische Deutschtum nach dem Kriege" (o germanismo brasileiro depois da guerra), foi publicada no Kalender für die Deutschen in Brasilien, em 1921. Não tem citação completa do autor (indicado como Dr. B.) algo comum nas publicações periódicas (inclusive nos jornais).

19 Cf. Kolonie Zeitung, Joinville, ano 71, n. 61:01, 08/04/1933. O autor está identificado pelas iniciais C.B. A palavra Volkstum - referenciada a povo - é um indicador da nacionalidade por critérios culturais e linguísticos, eventualmente usada em lugar de Deutschtum.

20 Cf. o editorial "Kalendermann Standrede" - Kalender für die Deutschen in Brasilien (1935:31-36).

21 Nos jornais e anuários vicejou (até 1939) uma literatura (contos, novelas, romances, poesia) que enalteceu a dupla pertença contida na categoria de identidade. Ela também expressou o orgulho pela manutenção da língua e cultura alemãs, porém num contexto teuto-brasileiro. Ver, por exemplo, o artigo "Teutonen Literatur", escrito por um dos principais literatos teuto-brasileiros, Ernst Niemeyer, publicado no Kalender für die Deutschen in Brasilien, em 1917.

22 Cf. Festschrift zum 60 Jährigen Bestehen der Deustsch - Evangelischen Schule Brusque, S. C., Brasilien, abril de 1933. Este folheto festejou o $60^{\circ}$ aniversário da Escola Evangélica Alemã da cidade de Brusque (SC).

23 Ver, por exemplo, o livro de Bethlem (1939) que discute a importância das "jornadas de civismo". Bethlem era oficial do exército e participou da "ocupação" de áreas de colonização por tropas especialmente treinadas para a ação nacionalizadora.

24 Deve ser observado que, na intervenção mais ampla, ruas, escolas e associações receberam novas denominações homenageando brasileiros ilustres, consideradas descabidas pela população local.

25 Entre outros nacionalistas, ver Bethlem (1939:X-XI), que apresenta a campanha nacionalizadora como "obra educacional por excelência", cujo objetivo é "trazer à unidade nacional estes milhares de brasileiros criados como estrangeiros - fazendo nossos irmãos os que, por educação mal conduzida, poderão ser nossos inimigos".

26 Sob muitos aspectos, esse posicionamento relacionado à escola de perfil étnico remete à atual "questão multicultural" (na definição de Hall 2003), relativa aos problemas de governabilidade apresentados por sociedades com diferentes "Comunidades culturais" que mantêm identidades separadas. A questão da educação em sociedades multiculturais e a tensão entre comunidades minoritárias e a escola (pública), no caso da Inglaterra, são analisadas por Rex (1997), e têm semelhança com os debates em torno do ensino particular teuto-brasileiro antes de 1938. 


\section{Referências bibliográficas}

BETHLEM, Hugo. 1939. Vale do Itajaí (Jornadas de Civismo). Rio de Janeiro: José Olympio.

BLOGOSLAWSKI, Ilson P. R. 2002. A escola alemã no Alto Vale do Itajaí: Sociedade Escolar Colônia Matador, 1892-1930. Rio do Sul (SC): Editora Nova ERa.

CÂMARA, Lourival. 1940. "Estrangeiros em Santa Catarina". Revista de Imigração e Colonização, I(4):681-718. . \& NEIVA, Arthur, H. 1941. "Colonização nipônica e germânica no sul do Brasil". Revista de Imigração e Colonização, II(1):39-119.

COUTO, R. Ribeiro. 1941a. "O problema da nacionalização". Revista de Imigração e Colonização, II(1):18-38. . 1941b. "Língua nacional e espírito nacional". Revista de Imigração e Colonização, II(1):788-798.

D'ARAGÃO, Ignes B. C. 1946. "A educação do imigrante". Revista de Imigração e Colonização, 7(3):303-322.

DALBEY, Richard O. 1970. The German private schools of southern Brazil during the Vargas years, 1930-1945. Tese de Doutorado, Indiana University, EUA.

DUARTE, Manoel. 1917. Os alemães em Santa Catarina. Rio de Janeiro: Tipografia do Jornal Comércio.

ENTRES, Gottfried. 1929. Gedenkbuch zur Jahrhundertfeier deutscher Einwanderung in Santa Catharina. Florianópolis: Livraria Central.

ERIKSEN, Thomas H. 1991. "The cultural contexts of ethnic differences". Man, N.S., 26(1).

FOUQUET, Carlos. 1974. O imigrante alemão e seus descendentes no Brasil. São Paulo: Instituto Hans Staden; São Leopoldo: Federação dos Centros Culturais 25 de Julho.
GELLNER, Ernest. 1983. Nations and nationalism. Oxford: Blackweel.

GERTZ, René. 1991. O perigo alemão. Porto Alegre: Editora da Universidade (UFRGS).

GUIBERNAU, Montserrat. 1997. Nacionalismos. Rio de Janeiro: Zahar.

HOBSBAWM, Eric J. 1990. Nações e nacionalismo desde 1780 . Rio de Janeiro: Paz e Terra.

JENKINS, Richard. 1997. Rethinking ethnicity. Londres: Sage.

KONDER, Marcos. 1929. "Einwanderung und Schulproblem". In: Gottfried Entres (ed.), Gedenkbuch zur Jahrhundertfeier deutscher Einwanderung in Santa Catharina. Florianópolis: Livraria Central. pp. 213-220.

KREUTZ, Lucio. 1994. Material didático e currículo na escola teuto-brasileira. São Leopoldo (RS): Editora Unisinos.

NEIVA, Arthur H. 1944. "O problema imigratório brasileiro". Revista de Imigração e Colonização, 5(3):468591.

PARK, Robert E. 1937. "Assimilation, Social". Encyclopaedia of the Social Sciences, II:281-283. Nova York: MacMillan.

PORZELT, Hans. 1937. Der deutscher Bauer in Rio Grande do Sul. Ochsenfurt: Verlag Fritz und Rappert.

RAMBO, Arthur B. 1994. A escola comunitária teuto-brasileilra católica. São Leopoldo (RS): Editora Unisinos. REX, John. 1997. "The concept of a multicultural society". In: M. Guibernau \& J. Rex (eds.), The ethnicity reader, nationalism, multiculturalism and migration. Cambridge: Polity Press.

SEYFERTH, Giralda. 1982. Nacionalismo e identidade étnica. Florianópolis: Ed. Fundação Catarinense de Cultura. 
2004. "A ideia de cultura teuto-brasileira: literatura, identidade e os significados da etnicidade". Horizontes Antropológicos, 10(22):149-197. . 2014. "Povoamento, alienígenas, eugenia e a política imigratória no Brasil (1808-1950)". In: M. Santos; R. Petrus \& A. L. Oliveira (orgs.), Recortes interdisciplinares sobre migrações e deslocamentos. Rio de Janeiro: Leo Christiano Editorial.

WAIBEL, Leo. 1958. Capítulos de geografia tropical e do Brasil. Rio de Janeiro: IBGE.

WEBER, Max. 1991. Economia e sociedade. Vol. 1. Brasília: Editora UnB.
WIEDERKEHR, Alessandra H. 2014. A gênese da escola alemá no sul do Brasil. Florianópolis: Editora Insular. WILLEMS, Emílio. 1940. Assimilação de populações marginais no Brasil. São Paulo: Companhia Editora Nacional. . 1946. A aculturação dos alemães no Brasil. São Paulo: Companhia Editora Nacional. . 1951. "Immigrants and their assimilation in Brazil". In: T. L. Smith \& A. Marchant (eds.), Brazil. Portrait of half a continent. Nova York: Dryden Press. 
SOCIALIZAÇÃO E ETNICIDADE: A QUESTÃO ESCOLAR TEUTOBRASILEIRA (1850-1937)
SOCIALIZATION AND ETHNICITY: THE MATTER OF SCHOOLING FOR GERMAN BRAZILIANS (1950-1937)

\section{Resumo}

Este artigo, postumamente publicado, trata da questão escolar de imigrantes alemães no Brasil, no período de 1850 a 1937. Nesse interregno, a incapacidade do Estado em assegurar o pleno acesso à escola pública para os filhos de colonos motivou a mobilização de lideranças comunitárias, religiosas e laicas para a organização de um sistema escolar particular de ensino na língua materna. As escolas denominadas "alemãs" perduraram até 1937, quando o governo, preocupado com a assimilação, fechou escolas ou produziu mudanças radicais nelas, no sentido do "abrasileiramento" em nome da segurança nacional. O artigo pretende explorar as interfaces entre etnicidade e nacionalismo que marcaram a socialização infantil nessas escolas.

Palavras-chave Etnicidade, Nacionalismo, Escolarização, Imigração alemã, Estado brasileiro.

\begin{abstract}
This posthumous article deals with the school issue of German immigrants in Brazil from 1850 to 1937. In this period, the State's inability to ensure full access to the public school for settlers' sons motivated the mobilization of community leaders, religious and lay orders for the organization of a particular school system in their mother tongue. The so-called "German" schools lasted until 1937, when the government, preoccupied with assimilation, closed or effected radical changes in schools toward the aim of "abrasileiramento" in the name of national security. The article intends to explore the interfaces between ethnicity and nationalism that marked child socialization in these schools.
\end{abstract}

Key words: Ethnicity, nationalism, schooling, German immigration, Brazilian state. 
SOCIALIZACIÓN Y ETNICIDAD: LA CUESTIÓN ESCOLAR TEUTOBRASILEÑA (1850-1937)

\section{Resumen}

Este artículo, póstumamente publicado, trata de la cuestión escolar de inmigrantes alemanes en Brasil, en el período de 1850 a 1937. En este interregno, la incapacidad del Estado en asegurar el pleno acceso a la escuela pública para los hijos de colonos motivó la movilización de líderes comunitarios, religiosos y laicos para la organización de un sistema escolar particular de enseñanza en la lengua materna. Las escuelas denominadas "alemanas" perduraron hasta 1937, cuando el gobierno, preocupado por la asimilación, cerró o produjo cambios radicales en las escuelas, en el sentido del "abrasilamiento" en nombre de la seguridad nacional. El artículo pretende explorar las interfaces entre etnicidad y nacionalismo que marcaron la socialización infantil en esas escuelas. Palabras-clave: Etnicidad, nacionalismo, escolarización, inmigración alemana, Estado brasileño. 